\section{DESATENCIÓN A LA SALUD ORAL INFANTIL COMO UN PROBLEMA DE SALUD PÚBLICA EN EL PERÚ}

\author{
NEGLECT OF ORAL HEALTH IN CHILDREN AS \\ A PUBLIC HEALTH PROBLEM IN PERU
}

\section{Akram Hernández-Vásquez ${ }^{1, a}$, Stalin Vilcarromero ${ }^{2, b}$, Juan Rubilar-González}

Sr. Editor. En la actualidad, existen diversos problemas de salud pública en el Perú que merecen atención prioritaria por las consecuencias permanentes que traen consigo y la gran cantidad de evidencia disponible de intervenciones costo-efectivas que avalan la disposición de los recursos para tales fines. Uno de ellos es la afectación a la salud oral (SO), que tiene a la caries dental como una de las enfermedades prevenibles más comunes en la niñez y que sin el cuidado necesario puede progresar hasta la destrucción y pérdida de la pieza dentaria afectada ${ }^{(1)}$.

Desde el año 2005 con la implementación del Plan Nacional de Salud Bucal se han realizado un conjunto de acciones vinculadas con la prevención y promoción de la SO. Como parte de esas acciones, el Seguro Integral de Salud (SIS) incluyó el financiamiento de una serie de prestaciones de salud oral en todas las edades para todos sus afiliados, con el propósito de incrementar el acceso a dichos servicios. Posteriormente, con la implementación del Aseguramiento Universal en Salud (AUS), el SIS diseñó convenios de pago por capitado, estos incluyeron incentivos por el cumplimiento de metas, basados en indicadores de actividades en SO, que tenían la intención de ampliar el número de atenciones y de realizar una medición y seguimiento de las mismas. Sin embargo, los resultados han sido desalentadores al verificar el incumplimiento de los objetivos trazados por los convenios, a lo que se suma que para el año 2015 se exceptuó la estimación de este tipo de indicadores ${ }^{(2)}$.

Al ver este escenario, creemos que es importante describir la población infantil que accedió a los servicios de salud dental tomando como referencia los datos de la Encuesta Demográfica y de Salud Familiar 2014

\footnotetext{
Instituto de Efectividad Clínica y Sanitaria. Buenos Aires, Argentina.

2 Sociedad Científica de Estudiantes de Medicina de la Amazonía Peruana (SOCIEMAP). Facultad de Medicina, Universidad Nacional de la Amazonía Peruana. Iquitos, Perú.

Universidad Mayor. Chile.

a Médico cirujano; ${ }^{\mathrm{b}}$ médico, magíster en Salud Pública; ${ }^{\mathrm{c}}$ sociólogo

Recibido: 11-06-15 Aprobado: 17-06-15

Citar como: Hernández-Vásquez A, Vilcarromero S, Rubilar-González J. Desatención a la salud oral infantil como un problema de salud pública en
} el Perú [carta]. Rev Peru Med Exp Salud Publica. 2015;32(3):604-5.
(ENDES) que incluye un capítulo sobre SO en niños, con la finalidad de mostrar algunas cifras que puedan servir de base para replantear estrategias y formular intervenciones en esta área. Asimismo, es pertinente cuantificar el acceso real que brinda el SIS a los servicios dentales, es decir, si la población asegurada accede o hace uso de los servicios de salud públicos. Lo anterior puede brindar una mirada general de cómo la falta de atención a la SO se convierte en un problema de salud pública que urge su abordaje y esfuerzos de solución.

El análisis de los datos nos muestra que durante el año 2014 , del total de menores de cinco años incluidos, solo el $26 \%$ accedió a servicios de salud dental. Asimismo, del número total de menores de cinco años que poseía afiliación al SIS, solo el $26 \%$ accedió a un servicio de salud dental. Respecto al lugar de atención de los menores afiliados al SIS, el $61 \%$ fue atendido en establecimientos del Ministerio de Salud y un $18 \%$ acudió a servicios dentales privados para atención. Respecto al área de residencia de los afiliados al SIS que recibieron servicios dentales, hay una clara desventaja del área rural comparada con el área urbana, en donde existe una brecha de 34 puntos porcentuales. Finalmente, teniendo en consideración el acceso según región geográfica, la región de la selva es la menos favorecida con solo un $11 \%$ de menores afiliados al SIS que accedieron a los servicios dentales (Tabla 1).

Tabla 1. Acceso y características de los menores de cinco años a la atención dental en el Perú, 2014

\begin{tabular}{lr}
\hline \multicolumn{1}{c}{ Menores de cinco años } & N (\%) \\
\hline Atención en servicios de salud dental \\
Sí & $2618(26,1)$ \\
No & $7398(73,9)$ \\
Afiliación al Seguro Integral de Salud & \\
Sí & $5444(54,4)$ \\
No & $4572(45,6)$ \\
Afiliados al Seguro Integral de Salud que han sido atendidos \\
en un servicio de salud dental \\
Sí & $1416(26,0)$ \\
No & $4028(74,0)$
\end{tabular}

Afiliados al Seguro Integral de Salud que han sido atendidos, según tipo de servicio de salud dental

$\begin{array}{lc}\text { Ministerio de Salud } & 868(61,3) \\ \text { EsSalud } & 246(17,4) \\ \text { Privados } & 259(18,3) \\ \text { Otros } & 43(3,0)\end{array}$

Afiliados al Seguro Integral de Salud que han sido atendidos en un servicio de salud dental, según área de residencia

$$
\text { Urbana } 951(67,2)
$$

Rural $465(32,8)$

Afiliados al Seguro Integral de Salud que han sido atendidos en un servicio de salud dental según región geográfica

\begin{tabular}{ll} 
Costa & $533(37,6)$ \\
Sierra & $721(59,9)$ \\
Selva & $162(11,4)$ \\
\hline
\end{tabular}


Los datos presentados nos llaman mucho la atención y revelan el limitado impacto de las políticas sanitarias en la SO. Por un lado, el gobierno menciona que el SIS ha ampliado su cobertura y acceso a los servicios de salud en el Perú, buscando eliminar la barrera económica del acceso ${ }^{(3)}$. Sin embargo, los resultados de la encuesta ENDES 2014 muestran que, si bien los menores tienen afiliación al SIS, no existe un acceso real de ellos a los servicios de salud pública, teniendo en consideración que un número significativo de menores ha recibido atención dental en el sector privado. Siendo así, podemos considerar que existe una problemática multifactorial y problemas estructurales que no son tomados en cuenta al momento de plantear soluciones a los diversos problemas de salud pública en el Perú y que terminan por desbordar las estrategias de solución planteadas.

En Perú, la mayor parte de las barreras que originan un problema de acceso a servicios de salud se concentran en los habitantes de menores recursos económicos y en aquellas zonas alejadas, por lo tanto, se deben implementar una serie de actividades destinadas al reconocimiento del problema y posteriormente, a su modificación o cambio. Ello requiere, en primer lugar, una mirada profunda a los factores individuales que influyen en el proceso de búsqueda de atención de nuestra población que dificulta el interés del cuidado de la salud. En segundo lugar, es fundamental poner atención a la oferta de servicios de salud públicos que incluyen la disponibilidad y oportunidad de la atención. Finalmente, a la obtención del tratamiento necesario que tiene que ver con la efectividad del tratamiento brindado, calidad en la atención y satisfacción del usuario.

En síntesis, la prevención y promoción de la salud oral infantil han sido inefectivas en el Perú, convirtiéndose en una oportunidad de mejora que, mediante intervenciones costo-efectivas, permitiría lograr resultados favorables por el bien de la salud pública y que debe ser un tema prioritario para incrementar el bienestar de la población infantil basada en políticas públicas coherentes y que sean sostenibles en el tiempo.

Fuentes de financiamiento: autofinanciado.

Conflictos de interés: los autores declaran no tener conflictos de interés.

\section{REFERENCIAS BIBLIOGRÁFICAS}

1. Selwitz RH, Ismail AI, Pitts NB. Dental caries. Lancet. 2007;369(9555):51-9.

2. Seguro Integral de Salud. Mirador GREP [Internet]. Lima: SIS; 2015 [citado el 20 de mayo de 2015]. Disponible en: http://www.sis.gob.pe/ipresspublicas/miradorgrep.html
3. Perú, Ministerio de Salud. Proyecciones del Seguro Integral de Salud al inicio de su segunda década [Internet]. Lima: MINSA; 2012 [citado el 20 de mayo de 2015]. Disponible en: www.sis.gob.pe/portal/paginas/10moAniversarioSIS/ Materiales/ProyeccionesSIS2daDecada.pdf

Correspondencia: Akram Hernández Vásquez

Dirección: Calle Gavilán 3856, Ciudad Autónoma de Buenos Aires, Argentina

Teléfono: (0054) 91122981572

Correoelectrónico:ahernandez@iecs.org.ar

\section{INCREMENTO DE AISLAMIENTOS DE Salmonella spp. PRODUCTORA DE $\beta$-LACTAMASAS DE ESPECTRO EXTENDIDO EN PACIENTES PEDIÁTRICOS DEL INSTITUTO NACIONAL DE SALUD DEL NIÑO}

\author{
INCREASE OF ISOLATION OF EXTENDED \\ SPECTRUM $\beta$-LACTAMASE-PRODUCING \\ Salmonella spp. IN PEDIATRIC PATIENTS \\ FROM THE INSTITUTO NACIONAL DE \\ SALUD DEL NIÑO
}

Edgar Gonzales Escalante

Sr. Editor. Los miembros del género Salmonella son importantes agentes etiológicos de gastroenteritis e infecciones, tanto en países desarrollados como en vías de desarrollo. A partir del año 2010, a través de la vigilancia bacteriológica con la Red Nacional de Laboratorios en el Perú, se detectó un inusual aumento de casos de Salmonella en aislamientos de origen humano, en su mayoría pediátricos, en diversos hospitales de Lima y aislamientos de alimentos ${ }^{(1,2)}$.

Aunque el tratamiento antimicrobiano no es necesario en la mayoría de los casos de salmonelosis, los antibióticos como las cefalosporinas de amplio espectro son usadas

\footnotetext{
Instituto Nacional del Niño. Lima, Perú.

Instituto de Medicina Tropical, Universidad Mayor de San Marcos. Lima, Perú.

a Tecnólogo médico; ${ }^{b}$ magíster en Microbiología

Recibido: 09-06-15 Aprobado: 17-06-15
}

Citar como: Gonzales Escalante E. Incremento de aislamientos de Salmonella spp. productora de $\beta$-lactamasas de espectro extendido en pacientes pediátricos del Instituto Nacional de Salud del Niño [carta]. Rev Peru Med Exp Salud Publica. 2015;32(3):605-7. 